\title{
Urgences
}

\section{Fragments autobiographiques}

\section{Carmen Huet}

Numéro 29, octobre 1990

\section{Éclats d'œuvre}

URI : https://id.erudit.org/iderudit/025606ar

DOI : https://doi.org/10.7202/025606ar

Aller au sommaire du numéro

\section{Éditeur(s)}

Urgences

\section{ISSN}

0226-9554 (imprimé)

1927-3924 (numérique)

Découvrir la revue

Citer ce document

Huet, C. (1990). Fragments autobiographiques. Urgences, (29), 64-66. https://doi.org/10.7202/025606ar d'utilisation que vous pouvez consulter en ligne.

https://apropos.erudit.org/fr/usagers/politique-dutilisation/ 


\section{Fragments autobiographiques Carmen Huet}

\section{Naissance}

Le premier cri proclamant mon existence coïncida à quelques minutes près avec le dernier soupir de cette personne que je ne connaîtrai qu'à travers les autres: ma propre mère. Bébé déjà meurtrier malgré lui qui, pour se frayer un passage vers la vie, amena inexorablement sa mère à emprunter celui de la mort. Premier cri, dernier soupir. N'est-ce pas, en fait, la même chose? Qui est le plus malheureux? Le bébé ou sa mère? Moi ou cette personne qui a aimé la vie au point d'en mourir? Ma mère ne se posera jamais la question. Moi, je suis plus ou moins condamnée à vivre avec des points d'interrogation tout autour de moi. C'est un peu ma sentence, ma punition, pour lui avoir survécu.

\section{Ode à la paresse}

Je me souviens de cet été sans date ni nom où, le pied dans le plâtre, je n'avais qu'à respirer la nature, qu'à me laisser bercer tout doucement dans la douce chaleur des après-midis ensoleillés, tout en dévorant des dizaines de photoromans, étendue sur le perron de ma maison. Que j’étais heureuse, cet été-là, de m'être cassé un pied.

\section{Récit}

Je la revois encore, sa vieille frimousse ridée guettant mon arrivée à travers les carreaux de sa fenêtre embuée. Venue briser sa solitude pour la partager avec elle, j'ai appris la vraie valeur des choses. Elle me parlait du passé. Je la rejoignais dans des temps hors de moi-même. Elle m'invitait à assister au récit d'elle-même. Je l'écoutais, extatique. Grand-maman était, je crois, la meilleure autobiographe qu'il m'ait été donné... d'écouter. 
Un vide... à écrire

Le jour de sa mort, grand-maman a laissé un vide derrière elle. Avec elle, toute une génération venait de s'éteindre, aussi toute une série de récits du bon vieux temps. Avec sa mort venait de naître une nouvelle génération et toute une autre série de récits à bâtir.

\section{Lui}

Je l'ai rencontré sans vraiment y croire. Je ne l'ai pas reconnu. Après une longue amitié de trois ans, l'amour est venu prendre le relais. Maintenant, je le reconnais. C'est lui.

\section{Naissances}

De la naissance d'une vie à la naissance d'une écriture: un pas. Alors, pourquoi cette peur viscérale qui remonte sans cesse à la surface dès qu'il s'agit d'accoucher de mots? Peur, en faisant naître cet embryon avant terme, de tuer tout désir d'en concevoir un autre?

Alors le fragment intervient, timidement. Comme le souffle saccadé d'une mère en attente de son premier enfant. L'autobiographie se dessine, condamnée à n'être que fragment, fût-elle un long récit de soi avec un début, un milieu et une fin. Utopie que ce désir de s'écrire entièrement. La mort, implacable, se dresse derrière la feuille blanche qu'on poursuit pas à pas, jusqu'à laisser tomber le crayon en fin de parcours.

Autobiographie fragmentée ou fragment autobiographique. L'autobiographe n'a qu'à courber l'échine et à accepter l'inévitable: il ne sera jamais auteur de sa vie entière. Il ne pourra que la vivre entièrement, et non l'écrire.

La vie, dès qu'elle figure sur papier, perd son flux tumultueux et incessant. À la recherche de son identité narrative, l'écrivain oublie de s'écrire, à force de chercher. Il n'arrive pas à s'écrire exactement comme il voudrait être. Les mots prennent le pas sur lui, le dépassent. À sa grande désillusion ou à son plus grand bonheur, qui sait, il découvre que son 
66

écriture ne lui ressemble pas, qu'elle n'est pas lui. Sa volonté de se dire ne s'efface pas pour autant. L'expression prend le pas sur l'écriture.

C'est là qu'une idée surgit, l'idée de mots creux, trop figés dans leur statut. Pour combler ce long vide, cette attente de l'écriture: la lecture. Le vide d'une vie, la vie vide d'un écrivain, comblée par la vie des mots des autres sur le papier. Pour un instant, l'instant d'une lecture, l'écrivain réfléchit sur lui-même. Il regarde la feuille pleine de l'écriture de l'autre, ensuite sa propre feuille blanche, et affronte la vérité en face. La vie est un vide à combler... de lui-même.

L'autobiographie s'annonce alors dans toute son intégrité. Mais comme si un plâtre empêchait encore l'écrivain de se mouvoir. Peur de la réalité, fuite dans la fiction, fuite immobile dans le silence des mots, ceux des autres qui sont mort-nés ou ceux de l'écrivain se faisant, qui sont en gestation.

Enfin, l'instant crucial arrive où la vie ressent le besoin de se figer d'elle-même sur le papier. Le désir d'écrire meurt à la naissance de l'écriture, en attendant de se manifester à nouveau, à un autre moment de la vie de l'écrivain. L'autobiographie naît, comme pour ressusciter la vie passée de l'écrivain, un présent mort à jamais mais que l'acte de configuration contribue à faire renaître. L'écrivain, ironie du sort, cherche l'immortalité dans l'écriture, lorsque cette écriture est celle de son autobiographie. La résurrection s'effectue au moment de la lecture, lorsqu'une personne se refigure une vie. Espoir il y a de vivre à jamais par les mots.

Le désir d'écrire, pourtant, est mort pour un bref instant. Lorsqu'on met sa vie sur papier, on a à la fois l'impression de la figer pour toujours, mais aussi de la faire s'échapper entièrement. Le sens à lui trouver accapare toute l'attention. Le désir de créer n'existe plus pendant ce temps. Le fragment apparaît alors comme les spasmes d'une personne à l'agonie. A sa mort, l'écrivain ne peut plus s'écrire, l'acte de mourir ne pouvant être que pré-figuré. L'autobiographie est condamnée à n'être que fragment. 